\title{
IZAAK WALTON KILLAM CHILDREN'S HOSPITAL Department of Anaesthesia
}

Vacancies will shortly exist at the Izaak Walton Killam Hospital for Children for up to two Active Staff Anaesthetists. The appointments will be offered jointly by the hospital and Dalhousie University Faculty of Medicine, and successful applicants will be granted an academic appointment within the University Department of Anaesthesia.

Applicants must hold the Fellowship of the Royal College of Physicians of Canada and should have had significant post-Fellowship training or experience in paediatric anaesthesia. Additional experience or special interest in one or another of paediatric cardiovascular surgery, paediatric pain service, paediatric intensive care, or research would be an asset.

In accordance with Immigration Regulations, this Notice is directed in the first instance to Canadian Citizens and Permanent Residents.

Interested physicians should write in the first instance to

Dr. James D. Morrison

Acting Head, Department of Anaesthesia

IWK Children's Hospital

5850 University Avenue

Halifax, Nova Scotia

$$
\text { B3J } 3 \text { G9 }
$$

\section{8th ANNUAL}

NEW YORK AWESTHESIOLOEY REVIEW

June 17-21, 1991

Waldort Astoria Hotel New York City

ALBERT EINSTEIN COLLEGE OF MEDICINEI MONTEFIORE MEDICAL CENTER AND

MOUNT SINAI MEDICAL CENTER

\section{FOCUS}

The 28th Annual New York Anesthesiology Review provides a comprehensive and integrated study of current practice that prepares participants for successlut performance on both the 1991 Written and Oral Board Examinations. This program also provides a thorough up-date for the practicing anesthesiologist emphasizing the latest pharmacologic and technologic advances in the lield.

\section{FORMAT}

GENERAL SESSIONS: Each day, all registrants meet in general session for six or seven presentations followed by questions and discussion (32 presentations over five days). Presentations focus on the seminal topics in anesthesia, conducted by acknowledged leaders in the field.

KEY-WORD REVIEWS: Following each General Session (Mon. - Thurs.) participants attend group discussions, team-laught by faculty from the Albert Einstein College of Medicine, and designed specifically for anesthesiologists working toward the written board examination.

BREAKFAST MEETINGS: In addition, faculty from the host institutions offer participants both small-group meetings covering case discussions and Special Workshops that explore the management of specific situations

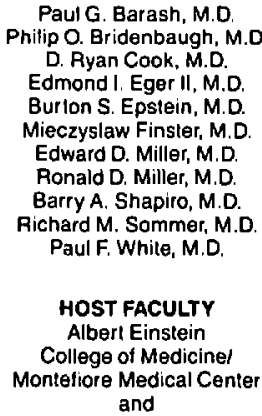
and

Mounl Sinai Medical Center
DIRECTOR

Elizabeth A M. Frost, M D. CO-DIRECTORS Paul L. Goldiner, M.D., O.D.S Joel A. Kaplan, M.D.

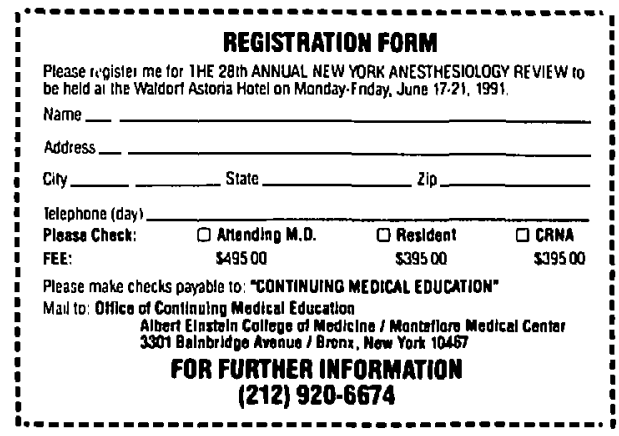

